Superalloys 2012: 12 ${ }^{\text {th }}$ International Symposium on Superalloys

\title{
ANALYSIS OF DEFORMATION SUBSTRUCTURES IN A NOTCHED LCF SAMPLE UNDER DWELL CONDITION IN A Ni-BASED SUPERALLOY
}

\author{
G.B.Viswanathan ${ }^{1}$, Ken Bain ${ }^{2}$, Dan Huber $^{3}$, S. Jha ${ }^{1}$, S. Sam ${ }^{3}$, J. Tiley ${ }^{1}$, Christopher Woodward ${ }^{1}$ and H.L. Fraser ${ }^{3}$ \\ ${ }^{1}$ Air Force Research Laboratory, Wright-Patterson AFB, OH 45433 \\ ${ }^{2}$ GE Aviation, Cincinnati, OH 45215 \\ ${ }^{3}$ Department of Materials Science and Engineering, The Ohio State University, OH 43210
}

Keywords: transmission electron microscopy, dislocations, deformation, low cycle fatigue, dwell-fatigue, superalloy

\begin{abstract}
Detailed transmission electron microscopy (TEM) studies were conducted on low cycle fatigue (LCF) sample of René 104 alloy samples tested under dwell conditions to analyze the deformation substructures. Specifically, the focus was to investigate the effect of crack length, in other words, stress intensity factor range $\Delta K$, on the deformation substructures. Thin foils were prepared by focused ion beam method (FIB) from two specific grains along the crack path at varying distances representing varying $\Delta \mathrm{K}$ values. The TEM analysis indicated that the character of deformation substructures significantly differed in these two grains. It is therefore speculated that local stress conditions and the grain orientations played a key role in the damage accumulation and subsequent substructure evolution. The regions below the fracture surface were also investigated. Detailed scanning electron microscopy (SEM) investigations of the grains immediately below the fracture surface revealed extensive microstructure degradation and potential hot spots for crack nucleation.
\end{abstract}

\section{Introduction}

The ability to resist crack growth under dwell-fatigue is a complex phenomenon in polycrystalline Ni-based superalloys used for turbine engine disk applications. Whether or not the fatigue process is controlled in a time independent manner (typically seen at low temperatures and higher cyclic frequency $>1 \mathrm{~Hz}$ or in time-dependent manner (seen at high temperatures, low cyclic frequency $<1 \mathrm{~Hz}$ or longer hold time between cycles), the fatigue crack growth rate (FCGR) is significantly higher in samples tested in an air environment compared to vacuum [1-3]. As a result, the debit in fatigue life has been attributed to the diffusion of oxygen into slip bands causing further slip-band-hardening ahead of the advancing crack [4]. In the latter case the debit is attributed to diffusion of oxygen to the grain boundaries making them fail prematurely. Accordingly, numerous studies, listed in ref. 3 have reported the failure mode switching from transgranular to mixedmode to entirely intergranular fracture. These failure modes can be significantly influenced further by factors such as temperature, hold time duration. More importantly, the microstructure has a major influence on FCGR. While the effect of microstructural features such as grain size [3] and grain boundary phases on low cycle fatigue are largely known [3], the understanding of the deformation substructure evolution ahead of the crack in the presence of $\gamma$ and $\gamma^{\prime}$ phases is still developing. This understanding is extremely important in designing the optimum heat-treatment for these alloys to balance the high temperature hold time crack growth resistance against creep properties.
Deformation by planar slip has been the central outcome of deformation studies in almost all of Ni-based superalloys evaluated under diverse loading conditions both at room temperature and at intermediate temperatures up to $700^{\circ} \mathrm{C}$. Reported planar deformation processes include shearing of both $\gamma$ and $\gamma^{\prime}$ by (i) strongly paired $1 / 2[110]$ unit dislocations, (ii) decorrelated $1 / 6<112>$ type Shockley partials causing intrinsic and extrinsic stacking faults [5,6] and micro-twinning [6,7]. These diverse deformation processes operate either individually or in combination depending on the temperature and the loading condition [6,7]. While numerous previous studies have focused on elucidating the deformation mechanism both during creep and during fatigue, only a handful of studies have paid attention to the deformation substructures during dwell-fatigue [8], which by definition exhibits a creep like condition between successive fatigue cycles. In this study, the primary focus is to study deformation substructures in notched samples of René 104, a Nibase superalloy tested under low cycle fatigue condition with hold-time dwell. Specifically, this study concentrates on the effect of varying $\Delta \mathrm{K}$, the stress intensity range, on the development of substructures. This is accomplished by primarily investigating deformation substructures of different grains along the crack path at varying distances from the crack initiation site.

\section{Experimental Details}

René 104, the Ni-based superalloy used in this study is a powder processed polycrystalline alloy. The alloy was supersolvus heattreated and had a coarse grain microstructure (grain size 15-30 $\mu \mathrm{m})$. The specimens were mechanically polished using standard metallographic processes and finished with 0.05 colloidal silica in a vibratory polishing unit. SEM techniques were used to characterize the microstructure of the specimens. Samples were etched with a $\gamma^{\prime}$ etchant $\left(2 \mathrm{ml} \mathrm{HF}, 20 \mathrm{ml} \mathrm{HNO}_{3}\right.$ and $50 \mathrm{ml}$ lactic acid), and imaged in the SEM with a back scattered electron (BSE) detector in "ultra-high resolution" (UHR) mode. Additional information on the imaging techniques are detailed elsewhere [9].

The dwell fatigue tests were conducted on circumferentially notched round bars $\left(\mathrm{K}_{\mathrm{f}}=1.77\right)$ at $\mathrm{GE}$ Aviation, Evendale. The samples were tested at $704^{\circ} \mathrm{C}\left(1300^{\circ} \mathrm{F}\right)$ at the peak stress of 848 $\mathrm{MPa}(123 \mathrm{ksi})$ and stress ratio $\mathrm{R}=0.05$. The samples were tested at this temperature using a cycle, which consisted of a $90 \mathrm{~s} \mathrm{dwell}$ at the peak load.

The fracture morphology of the fatigue samples was investigated in the SEM. Metallographic samples were prepared normal to the fracture surface to investigate the region beneath for fatigue 
damage. Site-specific thin foils were extracted by focused ion beam method (FIB) at various distances from the notched edge of the samples along the crack path from the grains beneath the fracture surface. The foils were used to examine the damage mechanisms as a function of crack length using an FEI, Tecnai$200 \mathrm{kV}$ transmission electron microscope (TEM).

\section{Results}

Figure 1a shows the typical starting microstructures of the alloy tested in this study. The super-solvus heat treatment resulted in coarse grain structure $(15-30 \mu \mathrm{m})$ with secondary and tertiary $\gamma^{\prime}$
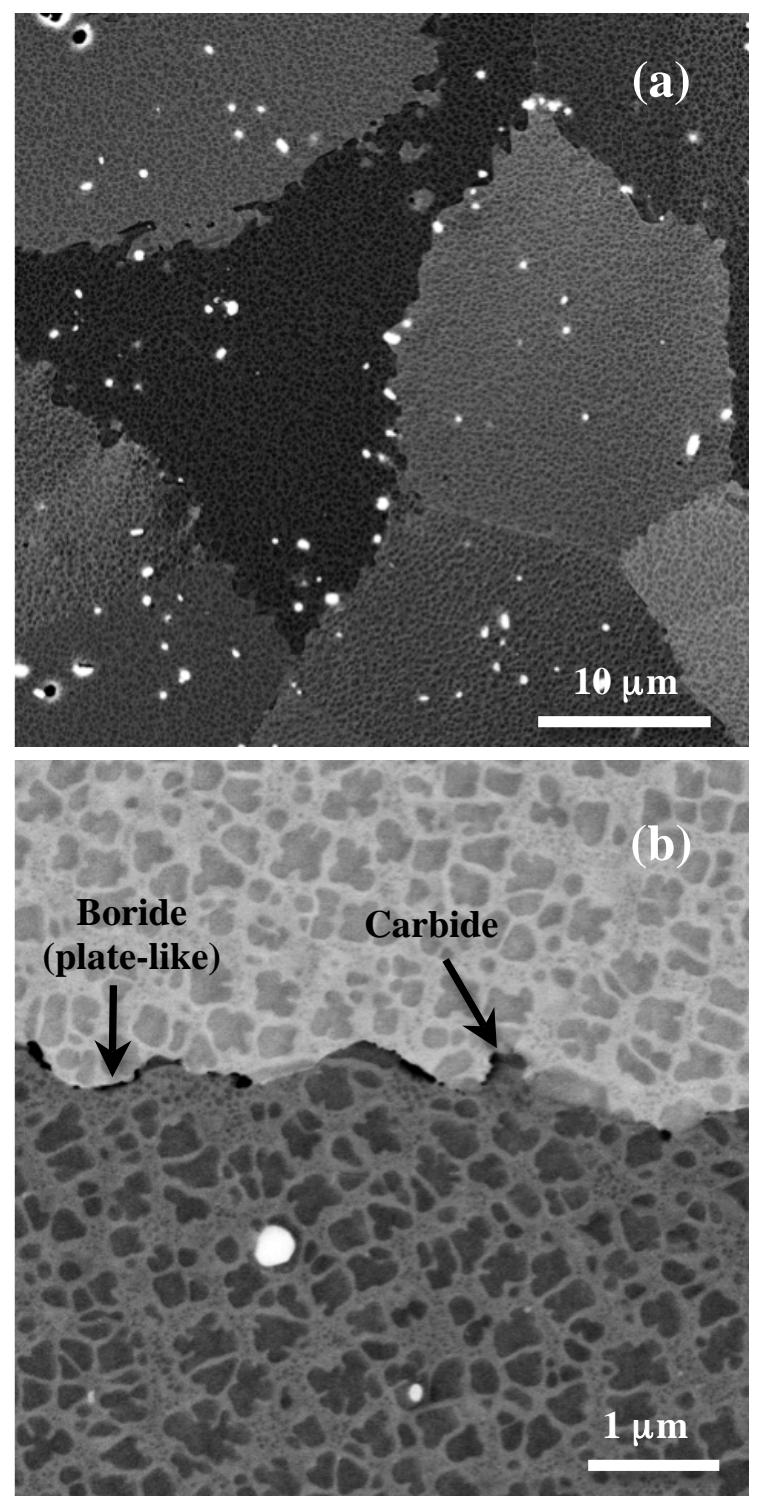

Figure 1. Back scattered electron (BSE) images showing (a) typical microstructure of the alloy, bright colored carbide particles can be seen distributed (b) higher magnification image of a typical grain boundary decorated with carbide and boride particles. Bi-modal distribution of $\gamma^{\prime}$ precipitates can be seen within the grains. precipitates in the grain interior, and carbides (bright regions) and borides at the grain boundaries. Blocky carbide particles can also be seen in the grain interior (Figure 1b). The borides at the
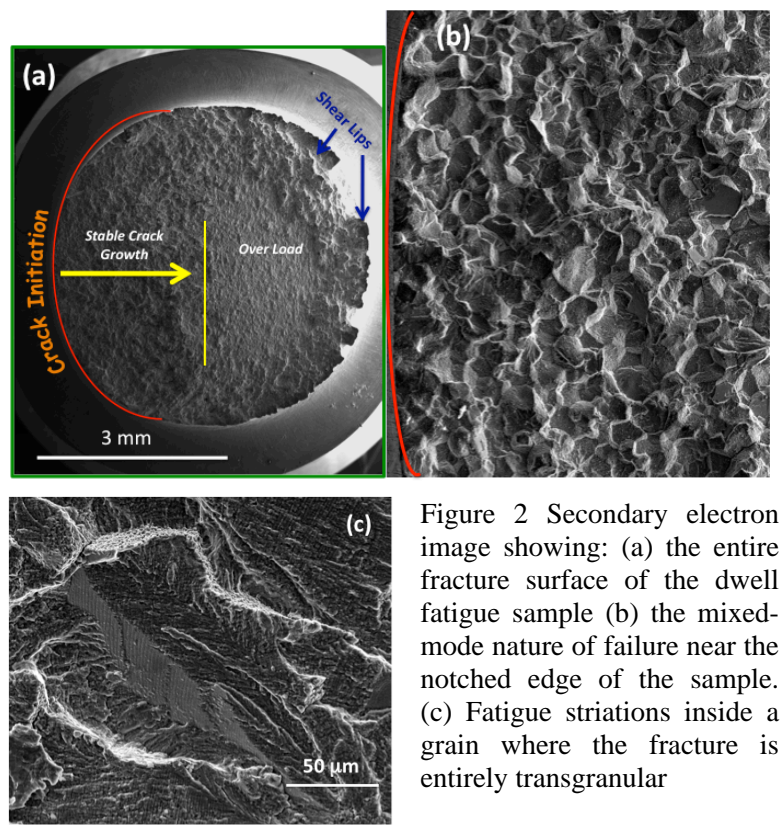

Figure 2 Secondary electron image showing: (a) the entire fracture surface of the dwell fatigue sample (b) the mixedmode nature of failure near the notched edge of the sample. (c) Fatigue striations inside a grain where the fracture is entirely transgranular

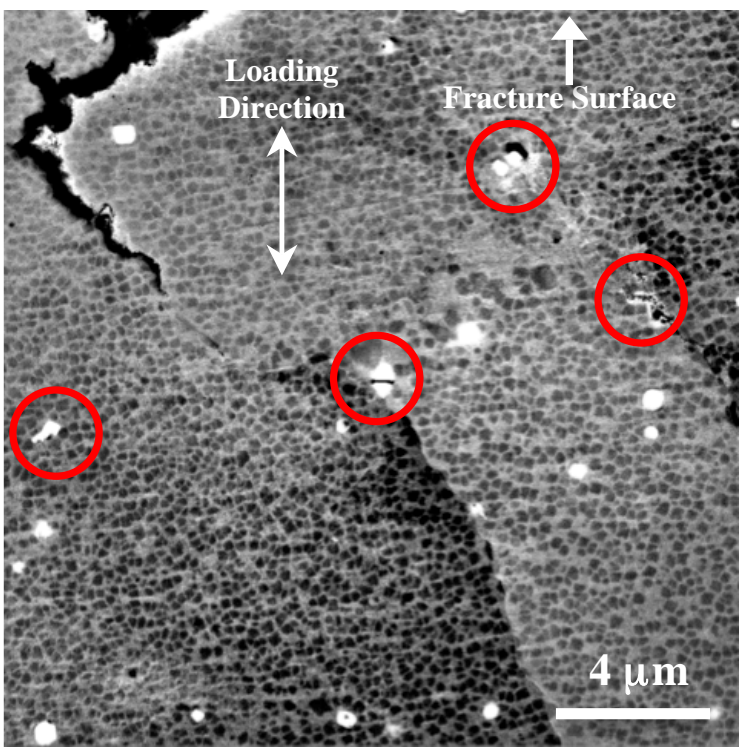

Figure 3 Back scattered electron (BSE) image showing the crack propagation along a grain boundary. Circled regions are the cracked carbide particles.

boundaries are thin, elongated and plate-like. The SEM image shown in Figure 2 delineates different regions of the fracture surface. The fatigue cracks seem to have initiated at multiple locations on the surface of the notched sample. The rest of the fracture surface can be divided into two regions, (i) the stable crack growth region where the fracture mode is predominantly 
intergranular. However, in isolated areas away from the notch, a number of grains can be seen fractured in transgranular fashion and (ii) the unstable crack growth region where the fracture is entirely transgranular. Secondary cracks can be seen near these grains well.

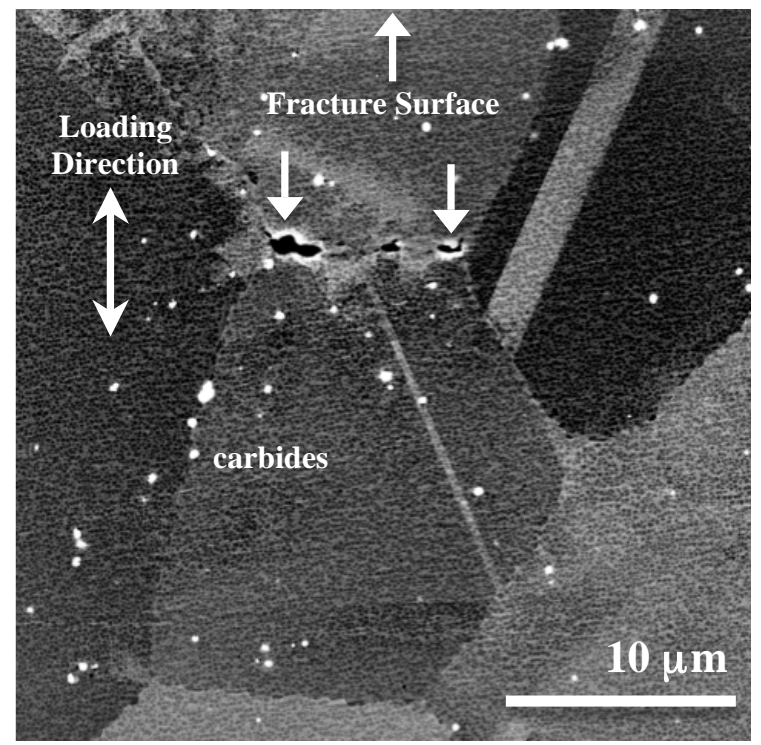

Figure 4. Back scattered electron (BSE) image showing intergranular crack nucleation at the triple grain junctions.

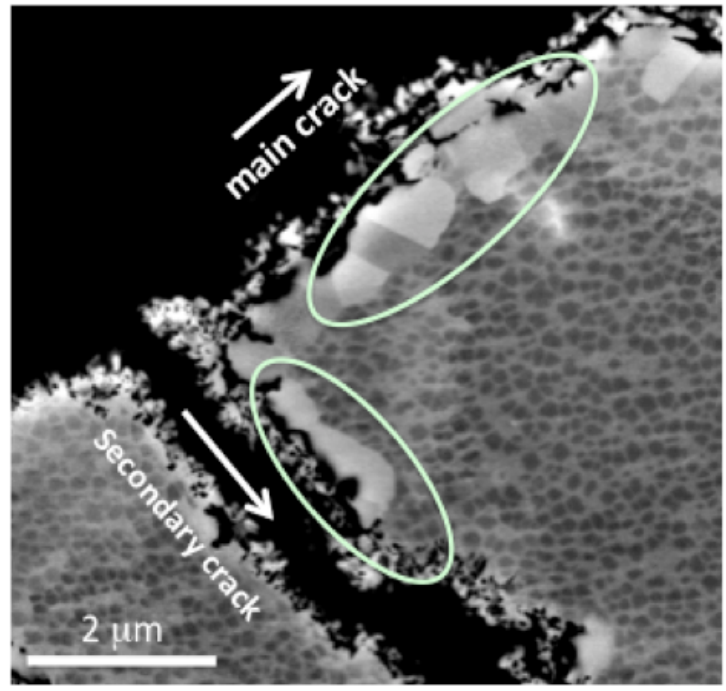

Figure 5. Back scattered electron (BSE) image showing recrystallization and the loss of $\gamma^{\prime}$ immediately beneath the fracture surface.

While the SEM images of the fracture surfaces were informative in terms of fracture and crack path morphology, the investigation of the region immediately beneath the fracture surface shed further light on the secondary damage processes, as shown in Figures 3 through 5 . Secondary intergranular cracking is evident in Figure 3. The mottled contrast from the grain interior arises from the severe deformation the adjoining grains undergo associated with the crack advance along the grain boundaries. Cracks can be seen nucleating along the carbide/matrix interface. Interestingly, carbide particles themselves appear cracked in the grain interior. This indicates the severity of the deformation of the grains along the fracture path. Nucleation of cracks at grain triple junctions is also seen frequently occurring as shown in Figure 4.

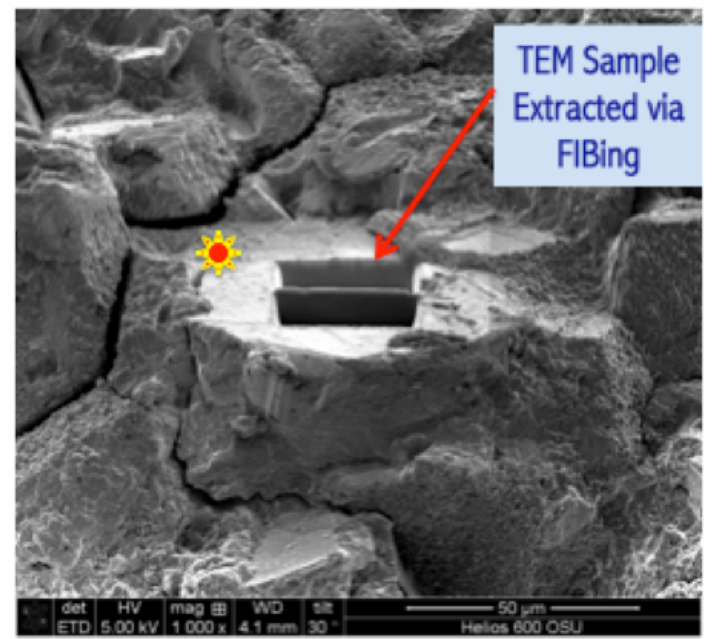

Figure 6 Secondary electron (SE) image showing TEM thin foil extraction from the fracture surface.

Another interesting observation is the change in the microstructure in the grain immediately beneath the fracture surface that was exposed to high temperature during fatigue. The exposed regions of the grain, as seen in Figure 5 show evidence of recrystallization of new smaller grains. In those regions, significant portion of $\gamma^{\prime}$ precipitates seem to have dissolved.

TEM samples were extracted from two grains from regions of high and low $\Delta \mathrm{K}$ that were approximately 1100 and $300 \mu \mathrm{m}$ from the crack initiation site, respectively. Figure 6 shows a FIB extraction of a slice, which was taken approx. $1100 \mu \mathrm{m}$ from the notch. Assuming these distances equal the crack depths and using the $\mathrm{K}$ solution expression given below [10], these locations represent $\Delta \mathrm{K}$ values of approximately 45 and $20 \mathrm{MPam}^{1 / 2}$ respectively. The TEM investigation of the deformation substructures from thin foils extracted from two different locations on the fracture surface are shown in Figures 7 through 9.

$\Delta \mathrm{K}=\mathrm{F}(\mathrm{a} / \mathrm{D}) \Delta \sigma \sqrt{\pi \mathrm{a}}$

where $\Delta \sigma$ is the applied stress range, a is the crack depth, D is net diameter of the specimen on the notched plane and $F(a / D)$ is a function representing the geometry correction factor [10].

In general, Figures 7 through 9 show that the dislocation density is very high in samples extracted from both locations consistent with the fact that these grains have been severely deformed due to crack propagations through them. There are both commonalities and differences in the nature of the substructures between the grains from regions of low and high low and high $\Delta \mathrm{K}$. In both grains the defect density is extremely high in the $\gamma$ matrix compared to the $\gamma^{\prime}$ precipitates. Both grains have planar and non- 

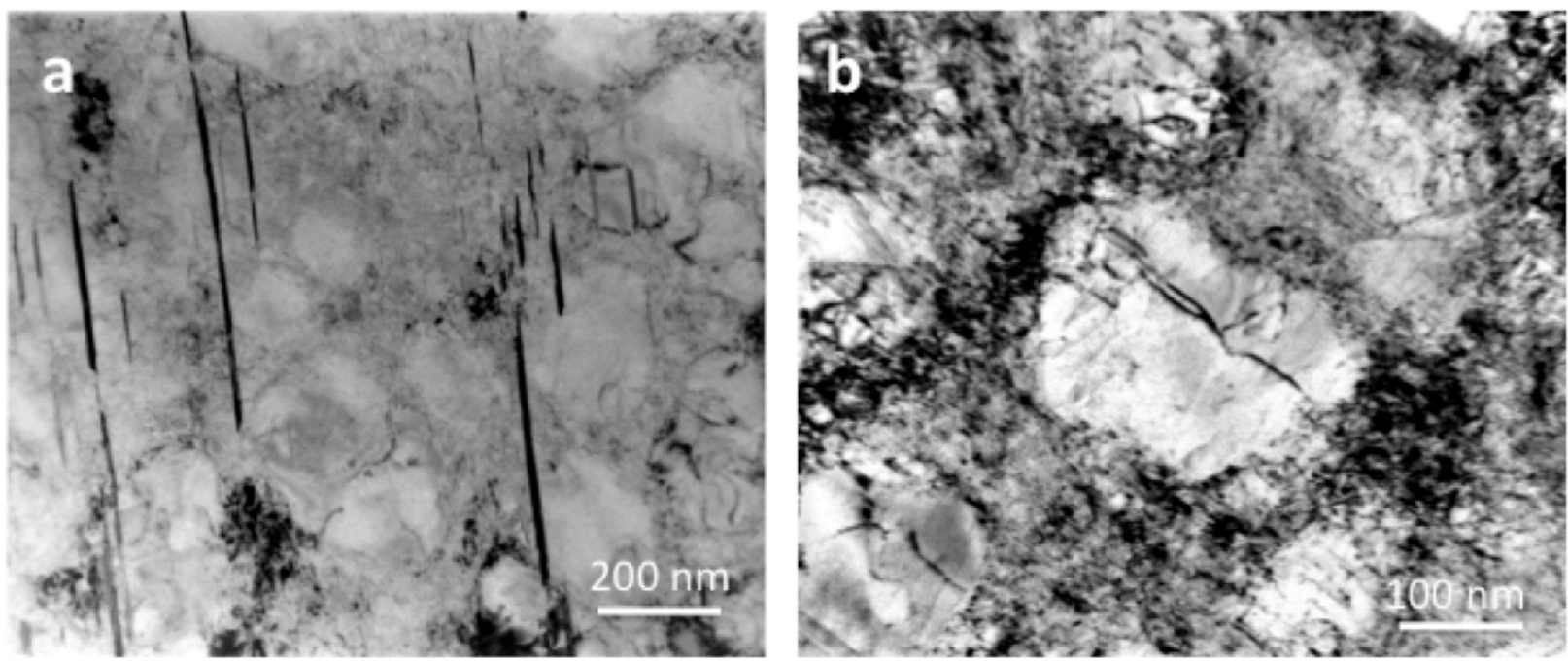

Figure 7 Bright field transmission electron microscopy (TEM) images showing (a) limited extended faulting and (b) extensive dislocation activity in both $\gamma$ matrix and $\gamma^{\prime}$ precipitates; in grain with low $\Delta \mathrm{K}$ grain.
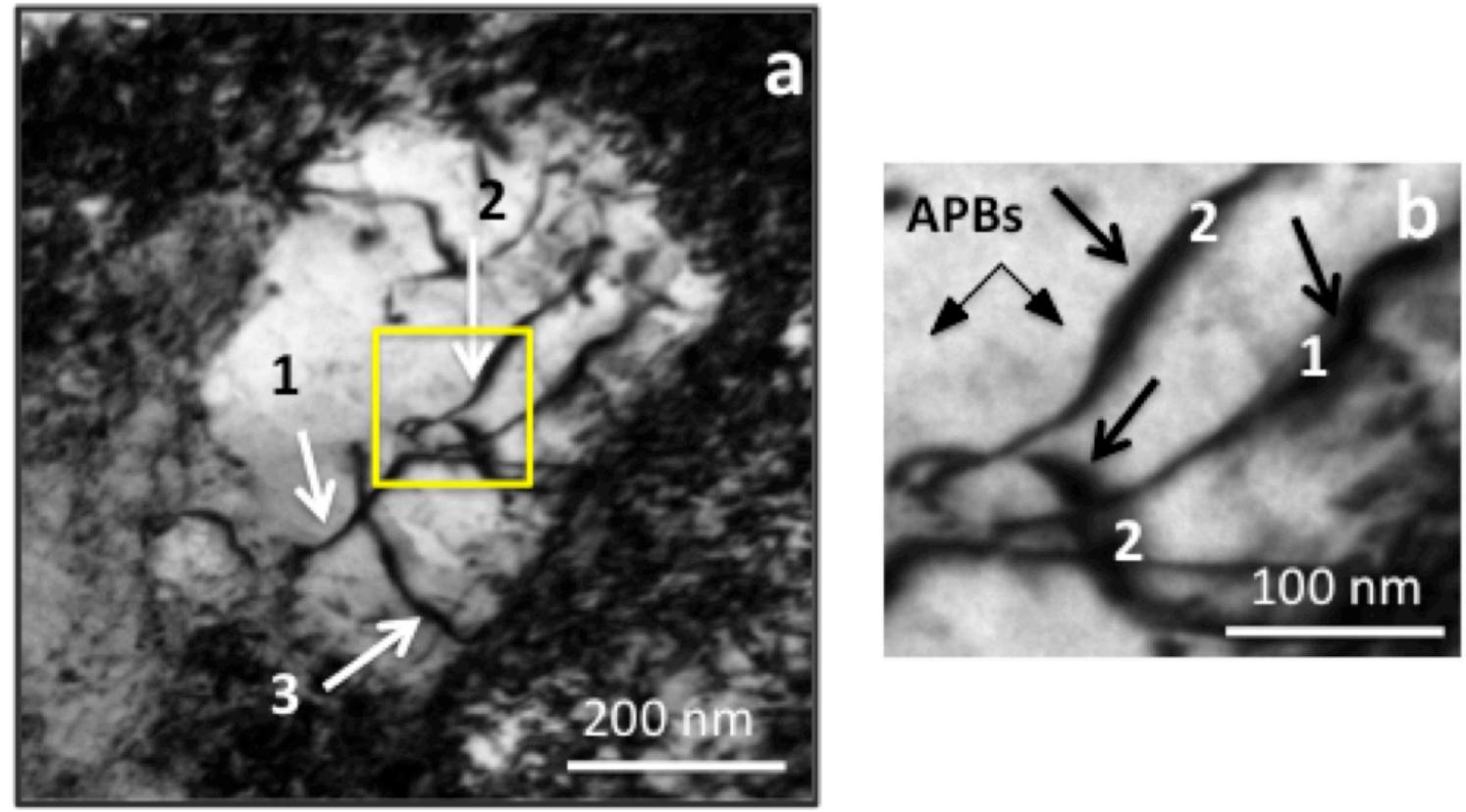

Figure 8. Bright field TEM images from grain with low $\Delta$ K showing (a) $1 / 2[110]$ superpartials (marked 1 through 3 ) shearing the $\gamma^{\prime}$ precipitate. (b) the perpendicular segments of the superpartial \# 2 have the cross slipped onto cube planes.

planar deformation substructures although the relative amounts of these are difficult to estimate at the present time. There are no incidences of microtwin formation in both of these grains, which have been reported to be the operating mechanism during creep at these temperatures [7]. The absence of twinning is also consistent with the fact that more non-planar deformation modes begin operating under dwell-fatigue conditions. The occurrence of planar and non-planar deformation is not only limited to $\gamma$ matrix. For example, Figure 8 shows the shearing of $\gamma^{\prime}$ precipitates by cross-slip. Detailed tilting analysis in the TEM has shown (Figure 8) segments of strongly paired $b=1 / 2[110]$ dislocations (marked by arrows) lie on the [001] cube planes. Cube cross slip is a wellknown phenomena known to occur at high temperatures [18-19]. On the other hand, there are significant differences between the deformation substructures between the samples. The deformation substructures in the grain from the low $\Delta \mathrm{K}$ regime consist of $1 / 2[110]$ unit dislocations mostly in the $\gamma$ matrix. In addition cross slipping of dislocations on to cube planes were seen within the $\gamma^{\prime}$ 
precipitates in the same grain. Conversely, the grain in the regime of high $\Delta \mathrm{K}$ contains a significant density of stacking faults (Figure 9 ) in the $\gamma$ matrix beside the dislocations. Analysis has shown that these are intrinsic stacking faults bounded by Shockley partial dislocations. De-correlated partial dislocations have been known to form during high temperature creep. Incidences of planar shearing of $\gamma^{\prime}$ precipitates by strongly paired $b=1 / 2[110]$ dislocations are more frequently seen in this sample compared to that of sample 1 where much more incidences of cube cross-slip based non-planar shearing were observed. The weak beam dark field image in Figure 8 shows strongly paired $1 / 2[110]$ (111) dislocations within the $\gamma^{\prime}$ precipitate. The dislocation debris in both samples is an important substructures feature not frequently seen in other high temperature deformation modes.

\section{Discussion}

The advantage afforded by the dwell-fatigue test in notched samples over the smooth bar is the ability to track fatigue damage near the crack since damage accumulation and crack initiation is largely localized to the notched section due to stress concentration

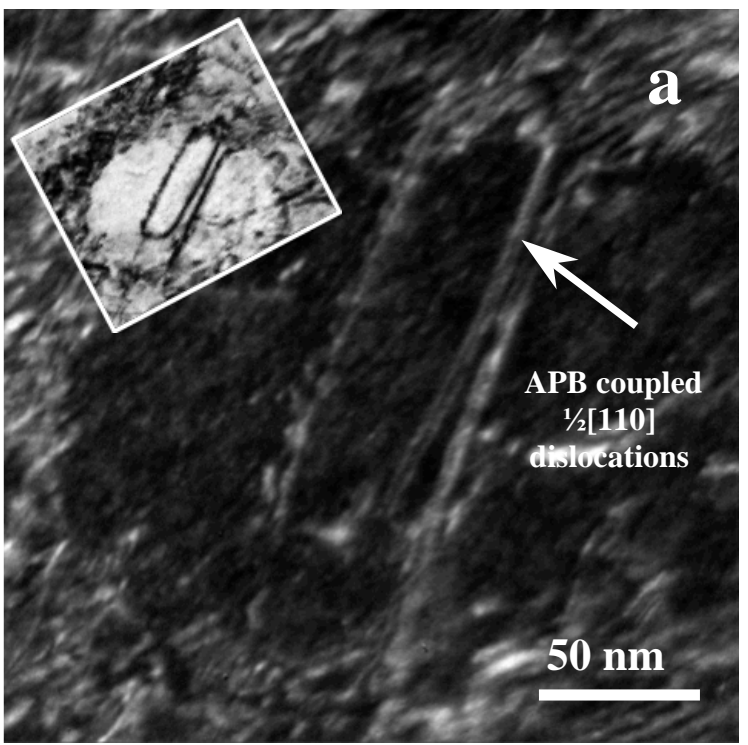

seen in samples tested in air has been attributed to factors such as (i) oxygen diffusion to the slip band and (ii) grain boundary embrittlement due to oxygen promoting faster intergranular failure. Once again the fracture mode also depends on whether the cracks nucleate on the surface or subsurface. When the cracks nucleate on the surface the fracture remains intergranular right through the failure due to the oxygen embrittlement effect mentioned above. On the other hand, when the crack nucleates at the subsurface grains, the fracture mode reportedly remains transgranular until the crack reaches the surface, which then changes to an intergranular mode due to exposure to oxygen [11] In our study the fracture morphology is uniform from the notched edge to the end of stable crack growth region, which is a mixture of intergranular and transgranular fracture. This suggests that the cracks might have nucleated from multiple locations. The grains near the notch that have fractured in a transgranular fashion suggest that the crack nucleation or short crack growth occurred in those regions within the slip bands. On the other hand, the fractured carbide particles seen beneath the fracture surface could themselves be the crack nucleation sites ahead of the advancing crack.

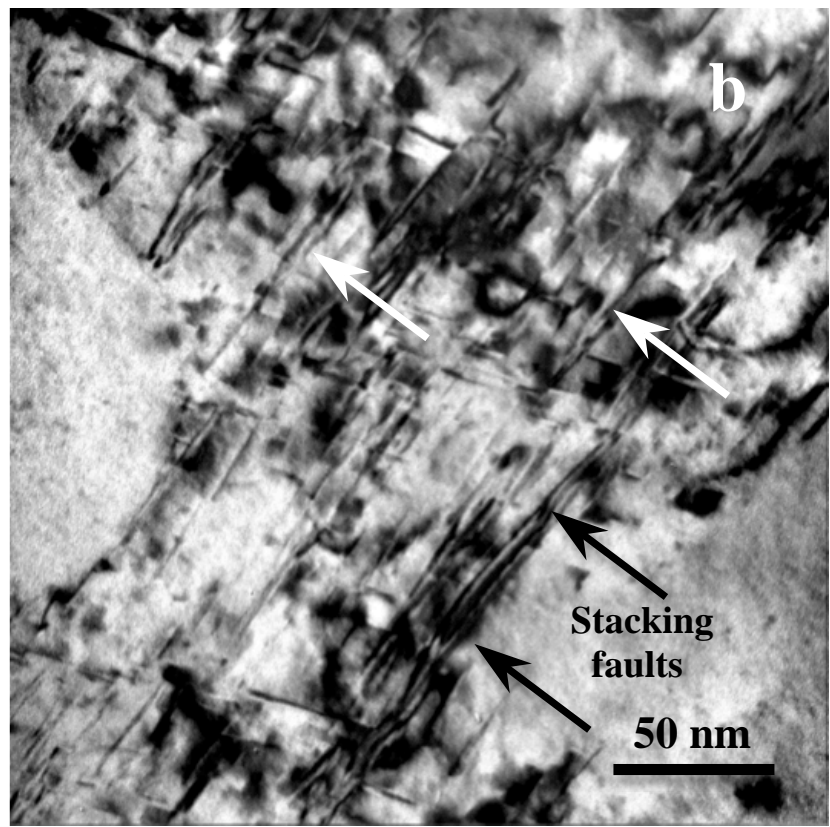

Figure 9. Bright field transmission electron images (TEM) showing (a) $1 / 2[110]$ superpartials within the $\gamma^{\prime}$ precipitate and (b) extensive intrinsic stacking faults in $\gamma$ matrix channels in a grain from a region of high $\Delta \mathrm{K}$.

at the notch while the damage elsewhere in the sample is relatively insignificant.

Fracture Morphology

The mostly intergranular nature of the fracture in the dwellfatigued sample in this study is consistent with the previous reports [11] where the grain boundary failures have been reported in samples tested in air. The fracture morphology in time dependent and time independent fatigue fracture has been the subject of discussion for many years. Most consistent observation agreed upon in many studies is the debit in fatigue life when the disk alloys are tested in air compared to vacuum. The shorter life
Studies have shown that below $450^{\circ} \mathrm{C}$ fatigue occurs though time independent damage mechanisms such a persistent slip band formation that promotes mostly transgranular failure. Above $550^{\circ} \mathrm{C}$, especially under dwell cycles, contribution from creep damage mechanisms where thermally activated processes such as diffusion, cross slip and climb become more prevalent.

\section{Deformation}

Planar slip band activity ahead of the advancing fatigue crack has been observed in a number of superalloys $[3,14]$. Boyd-Lee [10] has reported fracture morphology and slip band formation in RT 
fatigue study in Waspaloy as a function of $\Delta \mathrm{K}$. In that study, Boyd-Lee reported that crack nucleation occurred either within mode II slip bands or within carbide particles. During growth, at very low $\Delta \mathrm{K}$, only a few slip bands were observed while at very high $\Delta \mathrm{K}$ numerous slip bands occupied in a cylindrical zone ahead of the crack tip covering many grains. It was also reported that variation in grain size in the alloy, allowed the transition zone from short crack to long crack growth regime to span over a wide range of $\Delta \mathrm{K}$. This clearly demonstrates the importance of $\Delta \mathrm{K}$, that allows for a large variation in the local stress conditions, which can have huge impact on the fatigue crack growth rate. This type of studies, although provide very useful information, are limited in scope since these observations are made on the surface of the samples and consequently can not accurately describe the nature of crack tip interaction with local microstructural features such as $\gamma$ and $\gamma^{\prime}$ precipitates and grain boundaries etc. which are critical to the fundamental understanding of deformation mechanisms during fatigue. However, detailed investigation of deformation substructures as a function of crack length from crack initiation to short crack growth to long crack growth is still lacking.

In $\gamma / \gamma^{\prime}$ based superalloys, the deformation modes can change substanti ally depending on the stress, temperature and loading conditions [6,7]. Typically at room temperature, irrespective of the loading conditions the main deformation mode is through the propagation of strongly coupled $1 / 2[110]$ dislocations, which do not leave any extended fault either in the $\gamma$ matrix or the precipitates. On the other hand, in addition to $1 / 2[110]$ dislocations, shearing through faulting and twinning has been observed at high temperatures especially under creep conditions [5-7,16]. Extensive TEM analysis performed on the foils extracted from the dwell fatigue samples in this study also showed the presence of $1 / 2[110]$ dislocations, isolated faulting and extended faulting.

On the other hand, there were significant differences in subsidiary substructures between grains deformed under low and high $\Delta \mathrm{K}$. First, the grain with the low $\Delta \mathrm{K}$ had significant density of intrinsic stacking faults in the $\gamma$ matrix compared to the high $\Delta \mathrm{K}$ grain which had significant activity of $1 / 2[110]$ unit dislocations Secondly, within the $\gamma^{\prime}$ precipitates, the strongly coupled $1 / 2[110]$ dislocations were mostly co-planar, observed to lie mostly on (111) octahedral planes. On the other hand, significant cross-slip on to the cube planes was seen grains with higher $\Delta \mathrm{K}$.

These stacking faults seen in low $\Delta \mathrm{K}$ grain, arise from the dissociation of the $1 / 2[110]$ type unit dislocation, mainly driven by a low stacking fault energy, into two Shockley dislocations according to $1 / 2[110]-1 / 6[112]+$ ISF $+1 / 6[211]$ in the $\gamma$ matrix. These Shockleys seen in these samples are indeed deformationinduced under dwell fatigue. Shockleys have been observed under creep deformation at intermediate temperatures and they are referred to as de-correlated dislocations $(6,16)$. This essentially means that these individual Shockleys can now independently propagate despite the penalty introduced by the stacking fault at different velocities. Once dissociated, the mobility and therefore the shearing ability of these de-correlated Shockleys is now significantly depended on parameters such as, the resolved shear stress on individual Shockleys and the Orowan stress, in other words, the stress required for these Shockleys to push through the $\gamma$ channels in between the $\gamma^{\prime}$ precipitates.
Recent analytical and phase field modeling efforts by Unocic et. al., [16] have shown that the resolved shear stress could be vastly different between the leading and the trailing Shockleys depending on the orientation of the grains with respect to the applied stress, the angle between the slip vector, or in other words the Burgers direction and the stress axis and the spacing between the precipitates. As a result, if the Orowan stress is high enough both the leading and the trailing partial will be able penetrate and accomplish the deformation without dragging any intrinsic fault. On the other hand, if the leading partial possess a higher resolved shear stress than the trailing partial, the mobility of these decorrelated dislocation will be severely affected that can lead to extensive faulting in the $\gamma$ matrix, because of the restriction placed by the spacing between the precipitates. This is presumably may be the reason why extensive faulting in the $\gamma$ matrix occurs in the $\gamma$ matrix in a low $\Delta \mathrm{K}$ grain. This particular grain is presumably oriented such that the conditions were just right for faulting to occur for the reasons mentioned above where the resolved shear stresses were significantly different for the Shockleys along the slip direction. The resolved stress was probably insufficient even for the leading partial to be able to shear the $\gamma^{\prime}$ precipitate and as a result the stacking faults are mostly confined to the $\gamma$ matrix. This is consistent with similar observations in a Ni-based superalloy René 104, tested under creep conditions. The authors in that study, have reported extensive stacking fault in the $\gamma$ matrix and the bounding partials were seen locked in at the $\gamma / \gamma^{\prime}$ interfaces. Additional work is underway to determine the grain orientation with respect to the stress axis and the $\gamma^{\prime}$ precipitate size and distribution. On the other hand, the reason these short stacking faults in the $\gamma$ matrix are not prevalent in a high $\Delta \mathrm{K}$ grain may possibly be due to higher and sufficient resolved stress levels favoring $1 / 2[110]$ dislocations.

With respect to the substructures seen within the $\gamma^{\prime}$ precipitate, cube cross-slip has been known to occur for a long time under tensile loading at high temperatures in single crystals of binary and alloyed $\mathrm{Ni}_{3} \mathrm{Al}$, especially in the anomalous yield strength regions [18-20]. The cube cross slip has been reported to occur over a wide temperature regime due to the lower APB energy on the $\{100\}$ cube planes compared to $\{111\}$ octahedral planes. Primary cube slip has been observed in Alloy MERL 76 during high temperature high cycle fatigue condition [8]. However, this has been the first time such cube slip has been observed in $\gamma^{\prime}$ precipitates in a $\gamma / \gamma^{\prime}$ multi-component superalloy under dwellfatigue condition. However, it is unclear at this point why cube slip is more prevalent in grains with low $\Delta \mathrm{K}$ compared to high $\Delta \mathrm{K}$ grain where the slip is mostly observed to be coplanar. It is speculated that the severe local stress conditions imposed by higher $\Delta \mathrm{K}$, somehow prevents the dissociation of $1 / 2[110]$ unit dislocations.

Additional TEM foils are currently being extracted from and below the fracture surface for further analysis of the deformation mechanism.

\section{Conclusions}

The fracture morphology indicates that the fracture during dwellfatigue in samples tested in air reveals predominantly intergranular cracking with some isolated areas of transgranular growth. 
The microstructure below the fracture surface indicated that the crack frequently nucleates in grain triple points, especially where the twins within the grain intersects the grain boundaries.

A sample that was exposed to air during the test provided regions below the fracture surface with recrystallized grains with a significant loss of $\gamma^{\prime}$ precipitates.

TEM analysis indicates that deformation substructures vastly differ in grains with varying $\Delta \mathrm{K}$. The difference in the nature of substructures is attributed to the grain orientations and the local stress intensity factors.

\section{Acknowledgements}

The authors acknowledge funding from the AFRL Hybrid Disk Program and the support of D. Hardwick and insightful discussions with Mike Mills and Patrick Philips. The authors also acknowledge the support received from the Center for Accelerated Maturation of Materials (CAMM) at The Ohio State University for this research.

\section{References}

1. N.J. Hide, M.B. Henderson, and P.A.S. Reed, "Effects of grain and precipitate size variation on creep-fatigue behavior of Udimet $720 \mathrm{Li}$ in both air and Vacuum", Superalloys 2000, ed. T.M. Pollock et al., (Warrendale, PA, USA: The Minerals, Metals \& Materials Society, 2000), 495-503.

2. G. Onofrio, G.A. Osinkolu and M. Marchionni, "Fatigue crack growth of Udimet 720Li superalloy at elevated temperature", Int. J. Fatigue, 23 (2001), 887-895.

3. Andre Pineau and S.D. Antolovich, " High temperature fatigue of Nickel-base superalloys - A review”, Engg. Failure Anal., 16 (2009), 2668-2697.

4. P.A.S. Reed and I. Sinclair, "Temperature and environment effects on mode 1 crack propagation in Ni-base superalloys", Final report on MOD research contract 2040/515/MA, University of Southampton.

5. W.W. Milligan and S.D. Antolovich, "Yielding and deformation behavior of single crystal superalloy PWA 1480", Met. Trans. 18A (1987), 85-95.

6. G.B. Viswanathan et al., "Investigation of creep deformation mechanisms at intermediate temperatures in René 88 DT", Acta Materialia, 53 (10) (2005), 3041-3057.

7. G. B. Viswanathan et al., " Microtwinning during intermediate temperature creep of polycrystalline Ni-based superalloys: mechanisms and modeling", Philosophical Magazine A, 86 (2931) (2006), 4823-4840.

8. R.V. Miner, J. Gayda and R.D. Maier, "Fatigue and Creep Fatigue deformation of several Ni-base superalloys at $650^{\circ} \mathrm{C}$ ", Metallurgical Transaction A, 13A (1982), 1755-1765.

9. E.J. Payton, P.J. Phillips and M.J. Mills, "Semi-automated characterization of the $\gamma$ ' phase in Ni-based superalloys via highresolution backscatter imaging", Materials Science and
Engineering A 527 (2010) 2684-2692.

10. A. Carpinteri, R. Brighenti, and S. Vantadori, "Surface cracks in notched round bars under cyclic tension and bending," International Journal of Fracture, 28 (2006), 251-260.

11. Boyd-Lee, "Fatigue crack growth resistant microstructures in ploy crystalline Ni-base superalloys for aeroengine", Intl. Journal of Fatigue, 21 (1999), 393-405.

12. M. J. Caton and S.K. Jha, "Small fatigue crack growth and failure mode transitions in a Ni-base superalloy at elevated temperature", Intl. Journal of Fatigue, 32 (2010), 1461-1472.

13. M. J. Caton et al., "Divergence of mechanisms and the effect on the Fatigue life variability of Rene' 88 DT", Superalloys 2004 , ed. K.A. Green et al., (Warrendale, PA, USA: The Minerals, Metals \& Materials Society, 2004), 305-312.

14. J. Miao, T.M. Pollock and J. W. Jones, "Crystallographic fatigue crack initiation in Ni-bases superalloy René 88DT at elevated temperature", Acta Materialia, 57 (2009), 5964-5974.

15. J. Telesman et al., "Effect of microstructure on the time dependent fatigue crack growth behavior in a P/M turbine disk alloy", Superalloys 2008., ed. R.C. Reed et al., The Minerals, Metals and Materials Society, (Warrendale, PA, USA: The Minerals, Metals \& Materials Society, 2008), 807-816.

16. R.R. Unocic et al., "Dislocation decorrelation and relationship to deformation microtwins during creep of a $\gamma^{\prime}$ precipitate strengthened Ni-based superalloy", Acta Materialia, 59 (2011), 7325-7339.

17. P J. Phillips et al., "Low cycle fatigue of a Ni-based superalloy: Non-planar deformation"” Scripta Materialia, 62, (10) (2010), 790-793.

18. P. Veyssiere, "Weak-beam study of dislocations moving on $\{100\}$ planes at $800^{\circ} \mathrm{C}$ in $\mathrm{Ni}_{3} \mathrm{Al}$ ", Phil. Mag. A, 50 (1984), 189203

19. P. Caron and T. Khan, " $\{110\}$ slip in $\mathrm{Ni}_{3} \mathrm{Al}$ crept at $760^{\circ} \mathrm{C}$ along [001]", Phil. Mag. A, 60 (1989), 267-281.

20. Yu Jinjiang et al., "High temperature creep and low cycle fatigue of a nickel-base superalloy", Materials Science and Engineering A, 527 (2010), 2379-2389. 